\title{
ECOLOGICAL DIVERSITY OF SOME RESOURCE MEDICINAL MUSHROOMS OF THE GENUS PLEUROTUS IN THE NOVOSIBIRSK REGION
}

(C) 2019

Vlasenko Vyacheslav Aleksandrovich, candidate of biological sciences, senior researcher of Lower Plants Laboratory

Asbaganov Sergey Valentinovich, candidate of biological sciences, researcher of Introduction of Food Plants Laboratory

Vlasenko Anastasiya Vladimirovna, candidate of biological sciences, senior researcher of Lower Plants Laboratory Central Siberian Botanical Garden of Siberian Branch of Russian Academy of Sciences

(Novosibirsk, Russian Federation)

Abstract. In this paper the authors reveal features of substrate specialization and habitats distribution of the biotechnologically valuable medicinal resource species of Pleurotus pulmonarius mushrooms in the Novosibirsk Region. The authors show the distribution of the species on deciduous and coniferous tree species, in connection with substrate specificity, distribution in habitats and seasonal features of fructification formation. The studied species is confined mainly to deciduous trees; it was noted only once on Abies sibirica. In general, P. pulmonarius was recorded on 5 species of deciduous trees, most of the samples were collected on Betula pendula and Populus tremula. Less often the fungus is found on Sorbus sibirica, Populus sp., Acer negundo, Tilia cordata, Salix alba. P. pulmonarius develops in zonal small-leaved and mixed forests most often, it is rarely found in river floodplains and near-river communities. Quite often the fungus is found in artificial plantations, where it is one of the most common wooddecay fungi of anthropogenic habitats. Fructification of P. pulmonarius in the Novosibirsk Region occurs from May to October, its peak activity is in late summer - early fall (August-September).

Keywords: fungi; Pleurotus pulmonarius; oyster mushrooms; resource species; ecological structure; ecological diversity; distribution; substrate specificity; habitats; morphological types; fructification; phenology; molecular genetic verification; Novosibirsk Region.

$* * *$

УДК 582.572.226:581.522.4(571.14)

DOI 10.24411/2309-4370-2019-14107

Статья поступила в редакцию 24.06.2019

\section{TULIPA TSCHIMGANICA BOTSCHANTZ. В КОЛЛЕКЦИИ ЦЕНТРАЛЬНОГО СИБИРСКОГО БОТАНИЧЕСКОГО САДА СО РАН}

(C) 2019

Герасимович Людмила Владимировна, кандидат биологических наук, младший научный сотрудник лаборатории интродукции декоративных растений Центральный сибирский ботанический сад СО РАН (2. Новосибирск, Российская Федераџия)

Аннотация. В статье анализируются особенности сезонного развития Tulipa tschimganica Botschantz. в условиях региона-реципиента, приводятся сравнительные морфометрические характеристики ex situ и in situ. Представители вида $T$. tschimganica произрастающие в условиях высокогорья успешно акклиматизируются в Новосибирской области. Запоздалое цветение, устойчивость к вирусному заболеванию пестролепестности добавляет ценности данному виду в цветоводстве и озеленении в весенний период. Установлены температурные характеристики начальных этапов фенофаз. Начало цветения в шести из десяти лет наблюдений происходило во 2-й декаде мая. По продолжительности цветение можно характеризовать как короткое - 7-8 дней, средней продолжительности 10-12 дней и длительное - 13-15 дней соответственно. Было установлено, что, несмотря на высокие показатели максимальных и среднесуточных температур, пониженные низкие температуры увеличивают сроки цветения T. tschimganica, период цветения в регионе-реципиенте по сравнению с городом Ташкент сдвигается на два месяца и начинается со 2-й декады мая. У растений с экспериментального участка, в сравнении с in situ, изменяется в сторону увеличения диапазон изменчивости некоторых морфометрических параметров (высота растения, ширина листа, длина и ширина завязи, ширина плодов). Остальные исследуемые показатели остались в пределах in situ. У растений, выращенных из семян привезённых луковиц, изучается процесс онтогенеза. В настоящее время прегенеративный период онтогенеза составляет шесть лет. Успешное прохождение полного цикла развития годичных побегов и формирование полноценных зрелых семян характеризует данный вид как успешный для интродукции и использования его в озеленении города Новосибирск.

Ключевые слова: Tulipa tschimganica Botschantz.; тюльпаны; интродукция; акклиматизация растений; адаптация; сезонное развитие; фенология; характеристики начальных этапов фенофаз; морфометрия годичных побегов; Новосибирск.

\section{Введение}

Акклиматизация и интродукция растений (главным образом, в ботанических садах) являются не только первостепенными и важными в вопросе охра- ны и защиты полезных и редких растений. Но также, раскрывая проблему адаптации растений не только к изменению в климате, но и к антропогенному влиянию разного рода, они помогают прослеживать во- 
прос эволюционного развития вида или рода в целом на достаточно длительном промежутке времени. Так, реакция растений может сильно изменяться в зависимости от климатической зоны, тем самым показывая свой адаптационный потенциал [1-3].

Являясь богатым источником форм и сортов с декоративными качествами, род Tulipa привлекает внимание исследователей из разных разделов ботаники: интродукция, селекция, морфология, систематика.

Решая основную задачу ботанических садов изучение и сохранение растений, мы, исследуя закономерности морфологической и фенологической изменчивости, узнаем диапазон адаптационного резерва. Для этого следует использовать только представителей видов из природной флоры. Так, нами изучался вид из рода Tulipa $\mathrm{L}$.

Tulipa tschimganica Botschantz., как высокогорный вид (популяции произрастают на высоте не ниже 1400 м над уровнем моря), предпочитающий глубокие долины со скопившимся за зиму снегом и соседство со снежниками [4, с. 114], становится потенциально успешным в плане акклиматизации в условиях Западной Сибири [5, с. 109]. Запоздалое цветение, по сравнению с другими видами тюльпанов, и устойчивость к вирусному заболеванию пестролепестности добавляет ценности данному виду как объекту цветоводства и озеленения в весенний период. По культивированию данного вида в других регионах информация отсутствует.

\section{Цель и объект исследования}

Согласно современным представлениям, Tulipa tschimganica Botschantz. включен в подрод Tulipa [6, c. 296] как гибридный вид. З.П. Бочанцева включила данный вид в секцию Spiranthera [4, с. 17]. Растения в коллекции достигают в высоту до 38 см, имеют сизо-зеленые отклоненные листья, цветок одиночный желтый (в природе также встречаются красные и пестрые формы) с красными спинками наружных листочков околоцветника и желтыми тычинками, при полном раскрытии венчика цветок имеет звездчатую форму (рис. 1). Луковицы крупные, до 3 см, с темнокоричневыми покровными чешуями, которые с внутренней стороны покрыты редкими, длинными, прижатыми волосками. Значимых изменений в качественных признаках, описанных 3.П. Бочанцевой [4, с. 114-116], не наблюдается.

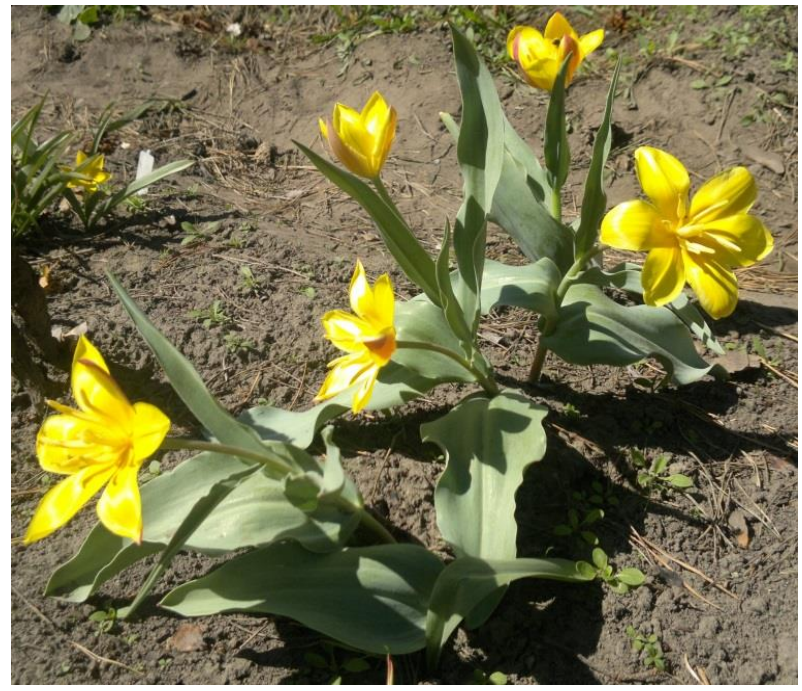

Рисунок 1 - Tulipa tschimganica Botschantz. в коллекции ЦСБС (2016 год, снимок автора)
Целью данной работы было изучение морфометрических изменений и фенологического поведения представителей вида Tulipa tschimganica Botschantz. в условиях города Новосибирска (ex situ).

\section{Методики исследования}

В процессе экспедиционных исследований, проведенных в марте - апреле 2009 г. в Республике Узбекистан (Ташкентский вилоят), в естественных местообитаниях, на задернованных осыпях северозападного склона горного массива Большой Чимган, окрестности села Чимган, 1700 м над ур. м., были собраны луковицы цветущих растений вида T. tschimganica, которые были высажены на коллекционном участке Центрального сибирского ботанического сада Сибирского отделения РАН (УНУ № USU 440534).

Привезенные луковицы в количестве восьми штук были высажены рядовым способом в открытом грунте экспериментального участка, первые два года почва была укрыта черным акрилом, агротехника в целом не отличается от классической для сортовых тюльпанов.

Фенологические наблюдения проводились по методике И.Н. Бейдеман [7].

\section{Результаты исследований и их обсуждение}

Собранные луковицы T. tschimganica при интродукции в условиях региона-реципиента характеризуются следующими особенностями сезонного развития (рис. 2).

В соответствии с многолетними фенологическими наблюдениями за растениями T. tschimganica в ex situ можно заметить, что начальные этапы всех основных фаз развития генеративных побегов имеют определенные экологические показатели (табл. 1). Например, по критерию среднесуточных температур воздуха: начало отрастания - от 5 до $10^{\circ} \mathrm{C}$, начало бутонизации - от 8 до $12^{\circ} \mathrm{C}$, начало цветения - от 6 до $15^{\circ} \mathrm{C}$, начало плодоношения - от 11 до $15^{\circ} \mathrm{C}$.

Тюльпаны являются весенними эфемероидами, которые используют накопленную влагу в почве и чувствительны к изменениям температурного режима. Согласно литературным данным [4], период цветения T. tschimganica в Ботаническом саду города Ташкент (Республика Узбекистан) (ex situ) отмечается со II декады марта, в коллекции ЦСБС СО РАН в период с 2010 по 2019 гг. начало цветения наблюдалось во II декаде мая шесть раз. По продолжительности цветение можно характеризовать как короткое - 7-8 дней, средней продолжительности - 10-12 дней и длительное - 13-15 дней соответственно.

В результате исследований нами были выделены и детально изучены температурные условия трех лет интродукции (рис. 3-5), в течение которых представители вида продемонстрировали короткое (2017 г., 7 дней), средне продолжительное (2016 г., 11 дней) и длительное (2018 г., 15 дней) цветение.

Как видно из графиков (рис. 3-5) минимальной, средней и максимальной температуры воздуха, в 2018 г. у растений наблюдалось продолжительное цветение. Поскольку начало цветения (22-24 мая) характеризуется понижением температур, а в после- 
Герасимович Л.В.

Tulipa tschimganica Botschantz. в коллекции Центрального сибирского ботанического сада СО РАН

дующие дни (несмотря на высокие показатели максимальных и средних температур) минимальные температуры, которые выпадали на ночное время, способствовали продлению периода цветения. Напротив, высокие показатели температур в 2017 г. сократили период цветение.

Также следует учитывать взаимосвязь продолжительности периода цветения с суммами положительных температур (табл. 2), так как для перехода из фазы цветения в фазу плодоношения растениям необходимо добрать от 120 до 200 градусов от суммы, что также сокращает или увеличивает период цветения.

У растений с экспериментального участка (табл. 3), в сравнении с in situ (табл. 4), изменяется в сторону увеличения диапазон изменчивости некоторых морфометрических параметров (высота растения, ширина листа, длина и ширина завязи, ширина плодов). Остальные исследуемые показатели остались в пределах in situ.

У растений, выращенных из семян привезённых луковиц, изучается процесс онтогенеза и всхожесть семян в открытом грунте при естественных условиях региона-реципиента. В настоящее время прегенеративный период онтогенеза составляет шесть лет. В таблице 5 указана всхожесть семян $T$. tschimganica на экспериментальном участке.
Выводы

Представители вида T. tschimganica имеют чувствительную ответную реакцию на изменения климатических параметров. Так, у растений в ex situ, в сравнении с in situ, изменяется в сторону увеличения диапазон изменчивости высоты побега, ширины листа, длины и ширины завязи, ширины плодов. Остальные исследуемые показатели остались в пределах in situ.

Продолжительность цветения напрямую зависит от суммы положительных температур: чем ниже среднесуточные температуры, тем больше времени нужно растению для перехода в фазу плодоношения, тем длиннее само цветение и наоборот.

Успешное прохождение полного цикла развития годичных побегов в условиях города Новосибирска и формирование полноценных зрелых семян, обладающих достаточно хорошей всхожестью, характеризует данный вид как успешный для интродукции и использования в озеленении города.

На протяжении всего периода исследований растения имели высокодекоративный эффект в весенний период, для которого в городе Новосибирск характерны резкие колебания температур.

\begin{tabular}{|l|l|l|l|l|}
\hline 2010 г. & & & & вегетация \\
\hline
\end{tabular}

\begin{tabular}{|c|c|c|c|}
\hline 2011 г. & 0. & ц. 10 & П. \\
\hline 2012 г. & o. & \begin{tabular}{|l|l|}
6.7 .8 \\
\end{tabular} & П. \\
\hline
\end{tabular}

\begin{tabular}{|l|l|l|l|l|l|l|l|l|}
\hline 2013 г. & & & 0. & б.6 & ц. 14 & П. \\
\hline 2014 г. & & & о. & б.19 & ц. 12 & П. \\
\hline
\end{tabular}

\begin{tabular}{|l|l|l|l|l|l|l|l|}
\hline 2015 г. & & & & о. & б.13 & ц.7 & П. \\
\hline
\end{tabular}

\begin{tabular}{|l|l|l|l|l|l|l|}
\hline 2016 г. & & о. & б.15 & ц.11 & П. \\
\hline
\end{tabular}

\begin{tabular}{|c|c|c|}
\hline 2017 г. & 0. & 6.10 ц. 7 \\
\hline
\end{tabular}

\begin{tabular}{|l|l|l|l|l|l|}
\hline 2018 г. & & о. & б.21 & ц. 15 & П. \\
\hline
\end{tabular}

\begin{tabular}{|c|c|c|c|c|c|}
\hline 2019 г. & & о. & б.11 & ц.11 & П. \\
\hline
\end{tabular}

\begin{tabular}{|l|c|c|c|c|c|c|c|c|c|c|c|c|}
\hline декады & I & II & III & I & II & III & I & II & III & I & II & III \\
\hline
\end{tabular}

\begin{tabular}{|l|c|c|c|c|}
\hline месяцы & апрель & май & июнь & июль \\
\hline
\end{tabular}

\footnotetext{
\begin{tabular}{|l|l|l|l|l|l|l|l|}
\hline o. & отрастание & б.x & бутонизация & ц. $x$ & цветение & П. & плодоношение \\
\hline
\end{tabular}

Рисунок 2 - Ритмы роста и развития Tulipa tschimganica в ЦСБС СО РАН в 2010-2019 гг. Примечание: $x$ - количество дней
} 


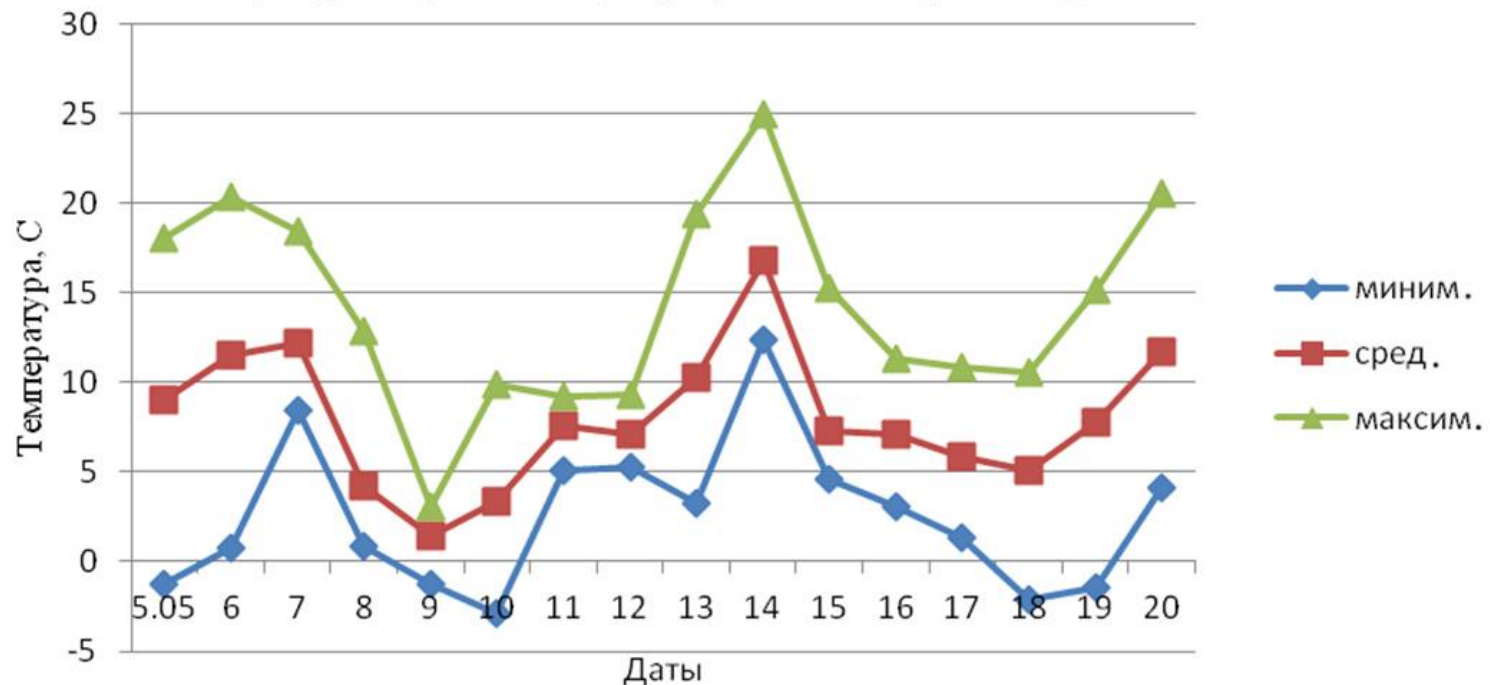

Рисунок 3 - Средней продолжительности период цветения (с 05.05 по 20.05)

Температурные условия периода цветения Tulipa tschimganica в 2017 г.

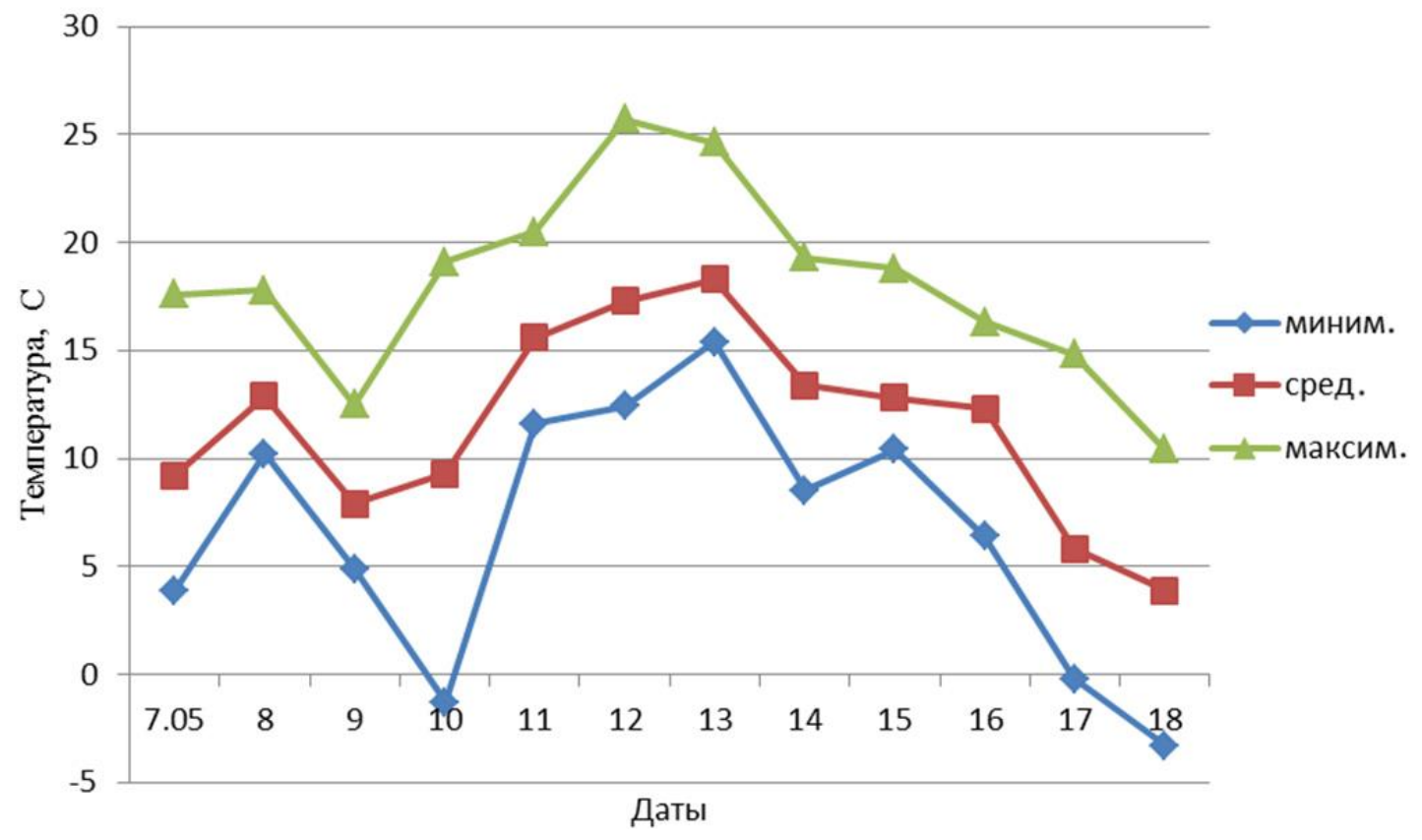

Рисунок 4 - Короткий период цветения (с 07.05 по 18.05)

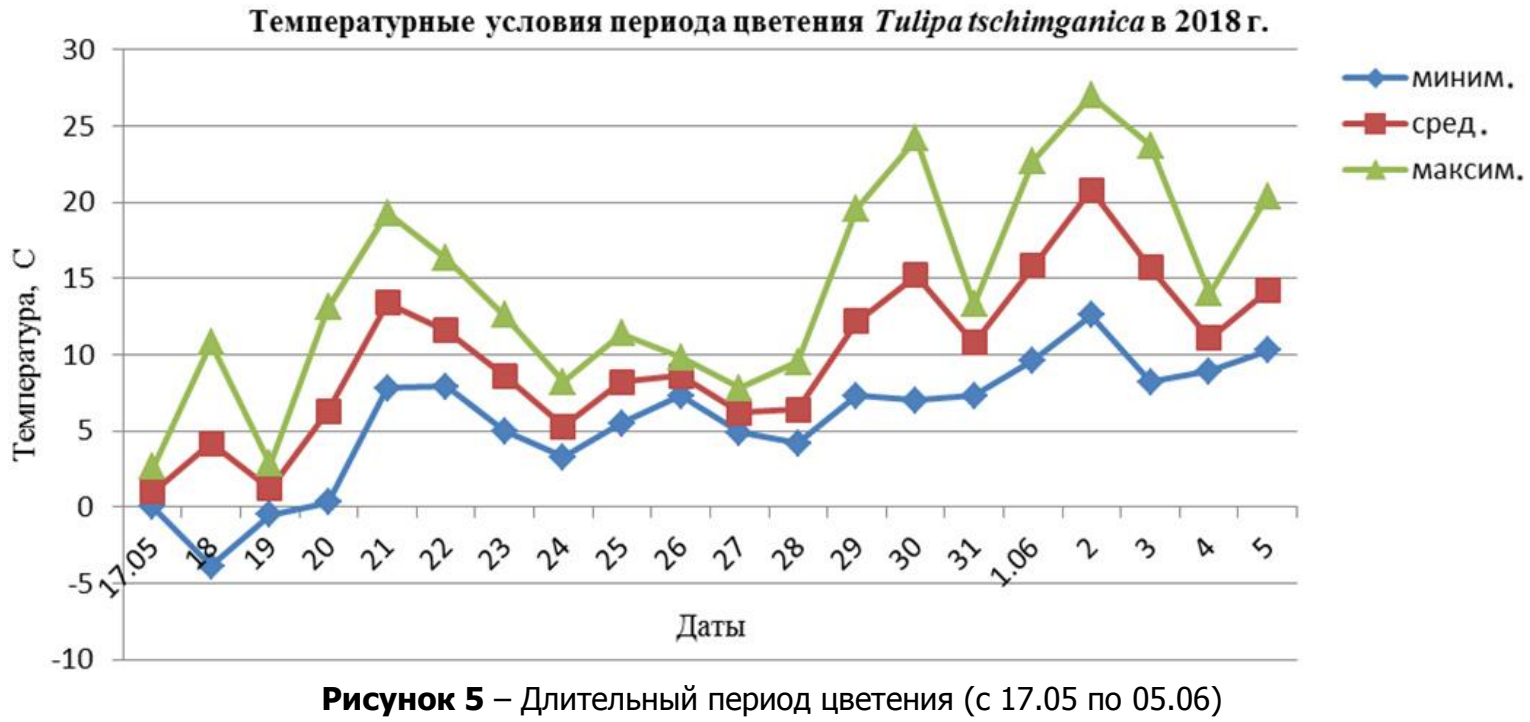


Герасимович Л.В.

Tulipa tschimganica Botschantz. в коллекции Центрального сибирского ботанического сада СО РАН

таблица 1 - Некоторые характеристики начальных этапов фенофаз у Tulipa tschimganica

\begin{tabular}{|l|c|c|c|c|}
\hline \multirow{2}{*}{ Показатели } & \multicolumn{4}{|c|}{ Начало фенофазы } \\
\cline { 2 - 5 } & отрастания & бутонизации & цветения & плодоношения \\
\hline Ср. $\mathrm{T}^{\circ}$ & $5-10$ & $8-12$ & $6-15$ & $11-15$ \\
\hline$\sum \mathrm{T}^{\circ}>0$ & $65-151$ & $176-260$ & $254-420$ & $380-518$ \\
\hline$\sum$ с.д. & $8-18$ & $13-20$ & $14-24$ & $19-43$ \\
\hline
\end{tabular}

Примечание. $C p . T^{\circ}$ - среднесуточная температура, $\sum T^{\circ}>0-$ сумма температур выше $0^{\circ} \mathrm{C}, \sum$ c.д. - сумма солнечных дней.

Таблица 2 - Взаимосвязь продолжительности цветения от сроков добора положительных температур

\begin{tabular}{|cc|c|}
\hline \multicolumn{4}{|c|}{2016 год (11 дней) } \\
\hline начало 05.05 & конец 20.05 \\
\hline $246^{\circ}$ & 2017 год (7 дней) \\
\hline & & \\
\hline начало 07.05 & & конец 18.05 \\
\hline $224^{\circ}$ & $353^{\circ}$ \\
\hline \multicolumn{4}{|c|}{2018 год (15 дней) } \\
\hline начало 17.05 & конец 05.06 \\
\hline $228^{\circ}$ & $424^{\circ}$ \\
\hline
\end{tabular}

Таблица 3 - Варьирование морфометрических параметров T. tschimganica в ex situ по годам

\begin{tabular}{|l|c|c|c|c|}
\hline \multirow{2}{*}{\multicolumn{1}{|c|}{ Параметры }} & \multicolumn{4}{c|}{ Годы } \\
\cline { 2 - 5 } & 2015 & 2017 & 2018 & 2019 \\
\hline Высота растения, см & $32,0-38,0$ & $16,7-24,4$ & $13,8-25,5$ & $23,5-24,5$ \\
\hline Высота цветоноса, см & $18,0-24,0$ & $4,5-9,0$ & $5,5-11,5$ & $15,5-16,0$ \\
\hline Длина верхнего листа, см & $12,4-14,5$ & $9,5-15,4$ & $7,5-15,0$ & 12,5 \\
\hline Ширина верхнего листа, см & $1,4-2,4$ & $1,1-2,0$ & $1,8-3,0$ & $2,5-2,6$ \\
\hline Длина среднего листа, см & $15,0-19,0$ & $13,4-16,9$ & $9,0-16,0$ & $14,5-15,0$ \\
\hline Ширина среднего листа, см & $2,8-4,8$ & $3,7-4,5$ & $3,2-5,7$ & 5,0 \\
\hline Длина нижнего листа, см & $16,0-19,0$ & $13,6-17,3$ & $10,5-18,0$ & $15,5-17$ \\
\hline Ширина нижнего листа, см & $4,5-7,7$ & $6,4-7,7$ & $5,4-8,0$ & 8,0 \\
\hline Число листьев (число особей) & $3(2)-4(2)$ & $3(2)-4(3)$ & $3(3)-4(1)$ & $3(2)$ \\
\hline Высота бокала, см & - & $4,1-4,8$ & $4,5-6,5$ & 6,0 \\
\hline Длина плода, см & $4,2-6,5$ & $4,2-6,0$ & - & $5,0-6,0$ \\
\hline Ширина плода, см & $2,1-3,5$ & $2,5-3,3$ & - & $2,5-3,0$ \\
\hline
\end{tabular}

Таблица 4 - Варьирование морфометрических параметров T. tschimganica in situ и ex situ

\begin{tabular}{|l|c|c|}
\hline \multicolumn{1}{|c|}{ Параметры } & in situ [5] & ex situ \\
\hline Высота растения, см & до 26 & $13,8-38,0$ \\
\hline Длина верхнего листа, см & до 20 & $7,5-15,4$ \\
\hline Ширина верхнего листа, см & до 2,2 & $1,1-3,0$ \\
\hline Длина нижнего листа, см & до 24 & $10,5-19,0$ \\
\hline Ширина нижнего листа, см & до 7,5 & $4,5-8,0$ \\
\hline Число листьев & $3-4$ & $3-4$ \\
\hline Длина завязи, см & 2,3 & $2,2-3,5$ \\
\hline Ширина завязи, см & 0,4 & $0,5-0,9$ \\
\hline Высота бокала, см & до 7 & $4,1-6,5$ \\
\hline Длина плода, см & до 11 & $4,2-6,5$ \\
\hline Ширина плода, см & 2,7 & $2,1-3,5$ \\
\hline
\end{tabular}

Таблица 5 - Всхожесть семян в условиях открытого грунта

\begin{tabular}{|c|c|c|c|}
\hline Год посева & Число семян & Число сеянцев & Всхожесть семян, \% \\
\hline 2013 & 543 & 99 & 18,23 \\
\hline 2015 & 370 & 42 & 11,35 \\
\hline 2016 & 172 & 0 & 0 \\
\hline 2017 & 164 & 96 & 58,54 \\
\hline
\end{tabular}

\section{Список литературы:}

1. Курочкина Н.Ю., Комаревцева Е.К. Лабазник вязолистный (Filipendula ulmaria (L.) Maxim.) в условиях культуры в Новосибирской области // Известия Оренбургского государственного аграрного университета. 2017. № 6 (68). С. 231-233.
2. Клименко 3.К., В Васильева О.Ю., Зорина Е.В., Дзюба О.В. Эколого-географическое испытание садовых роз в трех климатических зонах // Самарский научный вестник. 2019. Т. 8, № 1 (26). С. 35-42. DOI: 10.24411/2309-4370-2019-11105.

3. Герасимович Л.В. Tulipa kaufmanniana Regel. в коллекции Центрального сибирского ботанического 
сада Сибирского отделения Российской академии наук // Вестник Оренбургского государственного педагогического университета (Online). 2019. № 3 (31). C. 1-10. DOI: 10.32516/2303-9922.2019.31.1.

4. Бочанцева 3.П. Тюльпаны. Морфология, цитология и биология. Ташкент: Изд-во АН Узбекской CCP, 1962. $408 \mathrm{c}$.

5. Герасимович Л.В. Итоги первичной интродукции некоторых среднеазиатских тюльпанов в коллекции Центрального сибирского ботанического сада СО РАН // Успехи современной науки. 2017. Т. 1, № 8. C. 106-110.
6. Christenhusz M., Govaerts R., David J. etc. Tiptoe through the tulips - cultural history, molecular phylogenetics and classification of Tulipa (Liliaceae) // Botanical Journal of the Linnean Society. 2013. T. 172. P. 280-328.

7. Бейдеман И.Н. Методика изучения фенологии растений в растительных сообществах. Новосибирск: Наука, 1974. 256 с.

Исследования выполнены в рамках проекта VI.52.1.3 «Выявление путей адаптации растений к контрастным условиям обитания на популяционном и организменном уровнях", $A A A A-A 17-$ 117012610053-9 (номер госрегистрации).

\title{
TULIPA TSCHIMGANICA BOTSCHANTZ. IN THE COLLECTION OF THE CENTRAL SIBERIAN BOTANICAL GARDEN OF SIBERIAN BRANCH OF RUSSIAN ACADEMY OF SCIENCES
}

(C) 2019

\author{
Gerasimovich Lyudmila Vladimirovna, candidate of biological sciences, \\ junior researcher of Ornamental Plants Introduction Laboratory \\ Central Siberian Botanical Garden of Siberian Branch of Russian Academy of Sciences \\ (Novosibirsk, Russian Federation)
}

\begin{abstract}
The paper analyzes the features of seasonal development of Tulipa tschimganica Botschantz. in the conditions of the recipient region. Comparative morphometric characteristics of ex situ and in situ are given. Representatives of the species $T$. tschimganica growing in high mountains are successfully acclimatized in the Novosibirsk Region. Late flowering and resistance to viral disease variegation adds value to this species in floriculture and gardening in the spring. The temperature characteristics of the initial stages of phenophases are established. The beginning of flowering in six of ten years of observations occurred in the second decade of May. By duration, flowering can be characterized as short - 7-8 days, with an average duration of 10-12 days and a long one - 13-15 days, respectively. It was found that, despite the high rates of maximum and average daily temperatures, lower temperatures increase the flowering period of $T$. tschimganica. The flowering period in the recipient region, compared with the city of Tashkent, shifts by two months and starts from the second decade of May. The range of experimental plants morphometric parameters, such as plant height, leaf width, length and width of the ovary, and fruit width, increases. The rest of the studied parameters remained in situ. The study of the ontogeny of individuals grown from seeds collected from introduced plants is being carried out. To date, the plants are going through a long pregenerative period of ontogenesis. Successful completion of the full cycle of annual shoots development and the formation of highgrade mature seeds characterize this species as successful for introduction and use in gardening in Novosibirsk.

Keywords: Tulipa tschimganica Botschantz.; tulips; introduction; acclimatization of plants; adaptation; seasonal development; phenology; characteristics of initial stages of phenophases; morphometry of annual shoots; Novosibirsk.
\end{abstract}

$* * *$

УДК 58 (470.345) (045)

DOI $10.24411 / 2309-4370-2019-14108$

Статья поступила в редакцию 05.07.2019

\section{ЭКОЛОГО-БИОЛОГИЧЕСКИЕ ХАРАКТЕРИСТИКИ РОLYGONATUM MULTIFLORUM (L.) ALL. В УСЛОВИЯХ МОРДОВИИ}

(C) 2019

\author{
Лабутина Марина Викторовна, кандидат биологических наук, \\ доцент кафедры биологии, географии и методик обучения \\ Маскаева Татьяна Александровна, кандидат биологических наук, \\ доцент кафедры биологии, географии и методик обучения \\ Чегодаева Нина Дмитриевна, кандидат сельскохозяйственных наук, \\ доцент кафедры биологии, географии и методик обучения \\ Мордовский государственньй педагогический институт имени М.Е. Евсевьева \\ (2. Саранск, Российская Федераичия)
}

\footnotetext{
Аннотащия. В данной статье рассматриваются некоторые эколого-биологические особенности многолетнего травянистого растения - купены многоцветковой (Polygonatum multiflorum) cем. Liliaceae. Интерес к нему вызван тем, что численность этого вида лесостепной зоны сокращается вследствие возрастающей антропогенной нагрузки. Кроме того, купена является ценным лекарственным и декоративным растением. Исследования проводились в 2016-2017 гг. на территории Республики Мордовия, в условиях окрестностей крупного и провинциального городов. В ходе исследования были выявлены пространственная и возрастная структура четырех ценопопуляций купены. Определялись общие сроки вегетации купены и продолжитель-
} 